BMJ Open

Ophthalmology

\section{Implantation of Scharioth macula lens in patients with age-related macular degeneration: results of a prospective European multicentre clinical trial}

To cite: Srinivasan $\mathrm{S}$, Scharioth G, Riehl A, et al. Implantation of Scharioth macula lens in patients with age-related macular degeneration: results of a prospective European multicentre clinical trial. BMJ Open Ophthalmology 2019;4:e000322. doi:10.1136/ bmjophth-2019-000322

- Additional material is published online only. To view please visit the journal online (http://dx.doi.org/10. 1136bmjophth-2019-000322).

Received 13 April 2019 Revised 5 June 2019 Accepted 8 June 2019

Check for updates

(c) Author(s) (or their employer(s)) 2019. Re-use permitted under CC BY-NC. No commercial re-use. See rights and permissions. Published by BMJ.

For numbered affiliations see end of article.

Correspondence to Sathish Srinivasan; sathish. srinivasan@gmail.com

\section{ABSTRACT}

Objective To report the visual and refractive outcomes following monocular implantation of a supplementary (piggyback) Scharioth macula lens (SML) in previously pseudophakic eyes with age-related macular degeneration (AMD).

Methods and analysis Prospective European multicentre clinical trial. 50 eyes of 50 pseudophakic patients with either dry or previously treated and stable neovascular AMD for at least 6 months were included. The inclusion criteria were age over 55 , corrected distance visual acuity (CDVA) of $0.4-0.1$ (decimal), improvement of at least three lines of corrected near visual acuity (CNVA) when tested with $a+6.0$ dioptre $(D)$ reading addition at $15 \mathrm{~cm}$, compared with a $+2.5 \mathrm{D}$ reading addition at 40 $\mathrm{cm}$ using a standardised, self-illuminated Early Treatment Diabetic Retinopathy Study near vision chart. The SML intraocular lens (IOL) was implanted as an add-on/ piggyback IOL in the ciliary sulcus, monocularly in the better seeing eye of each subject meeting the inclusion criteria.

Results There were no intraoperative complications. One subject had the SML explanted in the postoperative period due to postoperative glare/halos. The mean CNVA improved from $0.23 \pm 0.12$ (decimal) preoperatively to $0.57 \pm 0.33$ at 1 year. The mean CDVA remained unchanged measuring $0.19 \pm 0.13$ preoperatively and $0.19 \pm 0.09$ at 1 year postoperatively.

Conclusion The SML appears to be safe and effective in improving the CNVA in patients with AMD. Data suggest that the CDVA remains unaffected following implantation. Further data are needed to assess the long-term safety and efficacy.

\section{INTRODUCTION}

Age-related macular degeneration (AMD) is a major cause of irreversible blindness in the western world. It affects about 11 million individuals in the USA and accounts for over half of blind and partial sight registration in the UK. ${ }^{1-3}$ About $8.7 \%$ of the world's population has AMD and the number is projected to increase to around 196 million in 2020 and 288 million in $2040 .^{1-3}$ AMD is categorised

\section{Key messages}

What is already known about this subject?

- Age related macular degeneration (AMD) is a major cause of irreversible blindness in the western world. Traditional methods of low visual rehabliation does not provide adequate results.

\section{What are the new findings?}

- IOL's that provide intraocular magnifaction might be a better way of helping these subsets of patients.

How might these results change the focus of research or clinical practice?

This research will help to focus on new technologies that can provide consistent, stable intraocular magnifiying devices to visually rehablitate patients with macular degeneration.

into early, intermediate and advanced stages based on the symptoms, number and size of drusen, hyperpigmentary or hypopigmentary changes in the macula and the presence or absence of choroidal neovascularisation. Dry AMD refers broadly to early and intermediate stages of the disease whereas the late stage is referred to geographic atrophy (GA), which involves the loss of retinal pigment epithelium followed by degeneration of the photoreceptors and thinning of the retina. ${ }^{4}$ Dry AMD accounts for $85 \%-90 \%$ of AMD cases and GA is responsible for approximately $20 \%$ of all cases of legal blindness. ${ }^{5}$ Current therapies for neovascular AMD target the abnormal neovascular growth through antibody-based inhibition of the vascular endothelial growth factors that are administered as intravitreal injections. However, no cure is currently available for dry AMD and the only preventive option is the Age-Related Eye Disease Study formulations, which reduce the risk of AMD progression by $25 \%-30 \%$ over a 5 -year period. $^{6}$ 


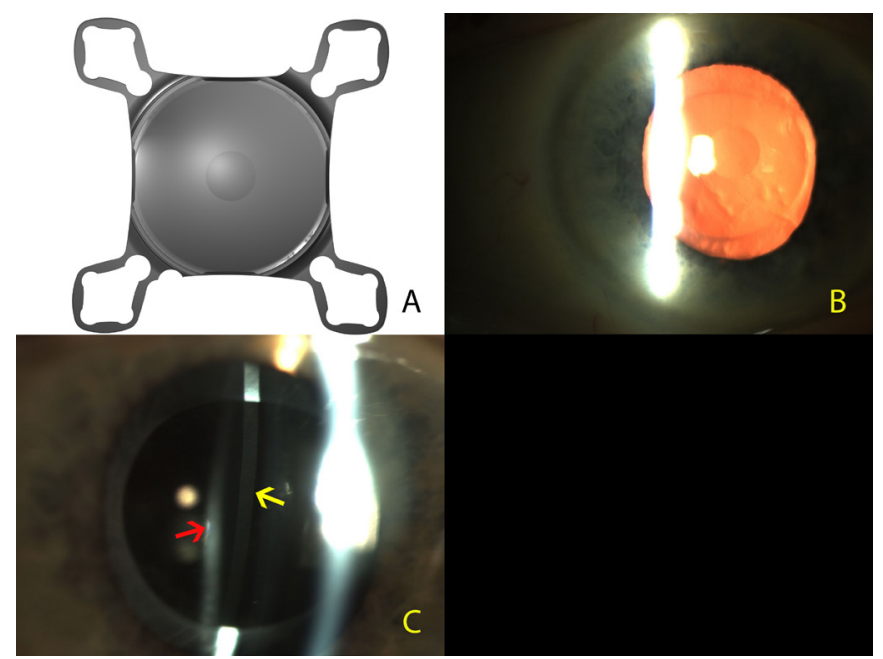

Figure 1 (A) Digital high-resolution photograph of the Scharioth macula lens. Note the central zone with $a+10.0 \mathrm{D}$ addition. (B) Clinical photograph of the Scharioth macula lens implanted in the eye. Note the 'oil droplet sign' of the central +10.00 addition on the intraocular lens (IOL). (C) Slit lamp illustrating the second Purkinje reflection (yellow arrow) from the Scharioth macula lens in the ciliary sulcus and the third Purkinje reflection (red arrow) from the primary intraocular lens in the capsular bag. Note the dark band between the two reflections showing that there is a clear space between the two IOLs.

The visual rehabilitation of patients with central scotomas resulting from either dry or treated neovascular AMD remains a challenge. Traditionally, these patients are referred for low vision rehabilitation for the provision of handheld or loop magnifiers and education on adequate light illumination for reading tasks. Even low vision rehabilitation does not provide uniformly improved quality of life in this patient group. ${ }^{7}$ A survey in the UK highlighted several problems with low vision services including fragmentation of services, lack of multidisciplinary care and inadequate communication between service providers. ${ }^{8}$ Recently, there has been interest in the use of various intraocular magnifying devices to enhance the near vision in patients with AMD. Strategies towards this end include the use of low-powered intraocular lenses (IOL), ${ }^{9}$ multifocal IOLis with a myopic target during cataract surgery, ${ }^{10}$ intraocular telescopic lens, ${ }^{11}$ implantable miniature telescopes (VisionCare Ophthalmic Technologies, CA, USA $)^{12}$ and IOL for visually impaired, which is a dual IOL system with a biconcave IOL in the capsular bag and a biconvex IOL in the anterior chamber (IOL-VIP, Soleko, Pontecorvo, Italy). ${ }^{13}$ However, these telescopic devices are technically challenging to implant requiring very large incisions, suturing, and produce restriction of visual field due to the optics of the telescope. Qureshi et $a l^{14}$ in a pilot study introduced the injectable intraocular telescope consisting of a high minus and a high plus lens implanted into the capsular bag and ciliary sulcus, respectively, through a $3.00 \mathrm{~mm}$ corneal incision. Although this device could be implanted through a small, self-sealing incision it had the same drawbacks of having a telescopic optics inside the eye causing severe restriction to the field of vision. Recently, there has been a report on the use of wavefront optimised IOL to provide enhanced quality of image on the macula during cataract surgery in patients with AMD. ${ }^{15}$ The Scharioth macula lens (SML) (A45 SML, Medicontur, Hungary) is a single-piece hydrophilic IOL implanted monocularly in the ciliary sulcus as a supplementary/piggyback IOL in pseudophakic eyes with AMD. The proof of concept of this technology was published in the Journal of Cataract and Refractive Surgery in 2015. ${ }^{16}$ A pivotal multicentre trial was conducted to determine whether the device can improve the near visual acuity in patients with moderate to profound visual impairment resulting from bilateral end-stage AMD; this report describes the 1-year safety and efficacy results of this study. The primary efficacy endpoint of this multicentre trial was visual acuity, as determined by the Early Treatment Diabetic Retinopathy Study (ETDRS) protocol charts. The SML implantation procedure was considered successful in patients with bilateral end-stage AMD if there was an improvement of $\geq 3$ lines of uncorrected near visual acuity (UNVA) in the implanted eye.

\section{MATERIALS AND METHODS \\ Study device}

The SML is a single-piece hydrophilic IOL designed for implantation in the ciliary sulcus as an add-on/piggyback IOL in previously pseudophakic eyes. This IOL has an overall diameter of $13.00 \mathrm{~mm}$ with an optic size of 6.0 $\mathrm{mm}$. The central $1.5 \mathrm{~mm}$ of the optic has an addition of $10.0 \mathrm{D}$ (figure 1 ). This translates to a magnification of $2.2 \times$ depending on the anatomy of the eye and the final reading distance. The remaining optical zone apart from the central $1.5 \mathrm{~mm}$ is refractory neutral. It has a four-point fixation with four flexible haptics, convex-concave configuration, with rounded edges to prevent iris chaffing. The morphology and the anatomical safety of this IOL was evaluated in pseudophakic eyes in a human cadaver eye laboratory study. ${ }^{17}$ The SML is injected through a custom-made disposable injector through a 2.2 mm self-sealing corneal wound.

\section{Study design}

This prospective, open-label, multicentre clinical trial was conducted following central European ethics approval from Freiburg Ethics Committee International (015/1189) and Hungarian Health Authority $(064153 / 2015 /$ OTIG) in May 2015. Patients were enrolled at practices from Scotland, UK $(n=10)$, Belgium $(n=2)$, Czech Republic $(n=8)$, Bulgaria $(n=5)$, Romania $(\mathrm{n}=3)$, Hungary $(\mathrm{n}=8)$ and two centres in Germany $(n=15)$. The recruitment of subjects commenced in October 2015 and the recruitment was completed in June 2016. Implanted patients were followed up at all study centres prospectively at day 1,1 week, 1, 3, 6 and 12 months, and visits scheduled through 24 months for longer term safety surveillance. 
Patient and public involvement

Patients were not involved in the design or the recruitment of the study subjects. The need for the study was discussed during a user group meeting of the clinicians across Europe. Each study centre clinician has taken up the responsibility of disseminating the results of the study to their individual patient groups.

\section{Patient enrolment}

Patients enrolled from the clinical practices of each investigator were at least 55 years of age, had bilateral, stable, central visual loss from either dry or treated and stable (at least for 6 months prior to recruitment) wet AMD as determined by fluorescein angiograph and/or spectral domain optical coherence tomography (OCT) and were pseudophakic in the study eye. Only the better seeing pseudophakic eyes of each patient were included in the study and the SML was implanted monocularly. All study eyes had a minimum anterior chamber depth of $2.8 \mathrm{~mm}$ (when measured from the corneal endothelium with an optical biometer), had a corrected distance visual acuity (CDVA) of 0.4-0.1 (decimal) on an ETDRS chart and demonstrated an improvement of three lines or more of corrected near visual acuity (CNVA) when tested with a standardised, self-illuminated ETDRS near vision chart held at $15 \mathrm{~cm}$ with a $+6.0 \mathrm{D}$ reading addition (with a trial lens placed in a trial frame with a back vertex distance of $12.5 \mathrm{~mm}$ ) compared with reading a self-illuminated ETDRS near vision chart with a $+2.5 \mathrm{D}$ reading addition (with a trial lens) at $40 \mathrm{~cm}$. In addition, patients were excluded if they had other ocular comorbidities including pseudoexfoliation, history of uveitis and complicated cataract surgery, and if they were unable to commit to the scheduled postoperative follow-up visits. Details on their diagnosis and previous AMD treatment are provided in table 1 . Following the above, subjects who met the inclusion criteria and willing to participate were provided with detailed written information and consent was obtained from all 51 subjects across seven study participating centres from Europe.

\section{Surgical procedure}

Under aseptic conditions a $2.2 \mathrm{~mm}$ clear corneal incision was fashioned either in the superior or temporal clear cornea based on surgeon's preference. A cohesive ophthalmic viscosurgical device (OVD) was injected into the anterior chamber and posterior chamber with care taken to open up the potential space in the ciliary sulcus posterior to the iris. The SML was removed from the container and placed on a single-use, custom-designed cartridge and was injected into the ciliary sulcus using a single-use custom injector. Following this, the trailing two haptics were tucked in the ciliary sulcus using a Sinskey hook. The OVD was aspirated out and intracameral acetyl choline (Miochol) was placed in the anterior chamber to avoid any pupillary capture and to confirm the centration of the central near vision addition of the SML in the pupillary area. Intracameral cefuroxime (1 $\mathrm{mg}$ in $0.1 \mathrm{~mL}$, Aprokam, Thea Pharmaceuticals, France) was injected into the anterior chamber at the end of the procedure. Postoperatively, all patients received topical steroids and a topical non-steroidal anti-inflammatory agent for a period of 4 weeks. The entire technique is shown in online supplementary video 1 (available at bjo.bmj.com). Preoperatively, all patients underwent a comprehensive ophthalmic examination, Goldmann applanation tonometry, fundus photography, fluorescein angiogram and OCT scan of the macula. Patients were examined postoperatively at days 1 and 7 and at months $1,3,6$ and 12 during which they underwent measurements of uncorrected distance visual acuity (UDVA) and CDVA, UNVA, slit lamp examination, intraocular pressure measurements, and dilated fundus examination and macular OCT. All patients participated in visual rehabilitation sessions at week 4 and at subsequent follow-up visits, where they were taught and encouraged to hold their reading material at $15 \mathrm{~cm}$ to enhance their reading potential.

\section{Statistical analysis}

All data were analysed using the GraphPad Prism V.7.0 software (La Jolla, CA, USA). Descriptive statistics were calculated in all cases. Statistical analyses were performed using Kruskal-Wallis test, followed by Dunn's multiple comparison test. Spearman's coefficient of rank correlation was used to find association between preoperatively estimated and postoperative measured visual acuity at 3

\begin{tabular}{llllll}
\hline Table 1 & Patient demographics, diagnosis and treatment summary & & \\
\hline Country & $\begin{array}{l}\text { Total number of } \\
\text { eyes enrolled }\end{array}$ & $\begin{array}{l}\text { Eyes with } \\
\text { dry AMD }\end{array}$ & $\begin{array}{l}\text { Eyes with } \\
\text { geographic atrophy }\end{array}$ & $\begin{array}{l}\text { Eyes with previously } \\
\text { wet AMD and treated }\end{array}$ & $\begin{array}{l}\text { Cumulative intravitreal } \\
\text { injections (n) }\end{array}$ \\
\hline Germany & 15 & 8 & 2 & 5 & 15 \\
Scotland, UK & 10 & 6 & 2 & 2 & 6 \\
Czech Republic & 8 & 7 & 1 & 0 & 0 \\
Hungary & 8 & 5 & 2 & 1 & 3 \\
Romania & 3 & 1 & 0 & 4 & 12 \\
Bulgaria & 5 & 3 & 0 & 0 & 0 \\
Belgium & 2 & 2 & 0 & 0 & 0 \\
\hline
\end{tabular}

$\mathrm{AMD}$, age-related macular degeneration. 


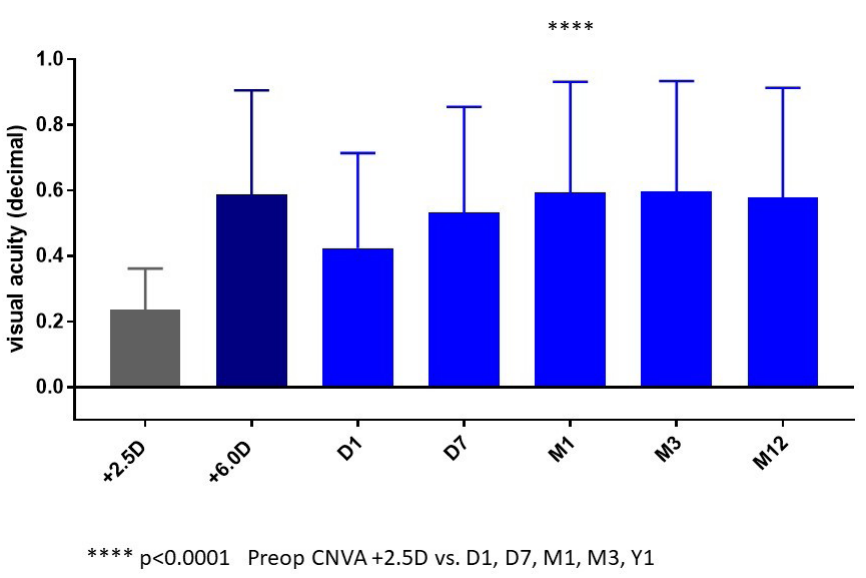

Figure 2 Graph illustrating the preoperative corrected near visual acuity (grey bar) and the postoperative uncorrected near visual acuity at various time gates. CNVA, corrected near visual acuity (light blue bars). Dark blue bar shows the preoperative CNVA at $15 \mathrm{~cm}$ with $+6.0 \mathrm{D}$ addition (estimated vision)

months. Differences were considered statistically significant when $p$ values were less than 0.05 .

\section{RESULTS}

There were no intraoperative complications. One subject had the SML explanted at month 3 in the postoperative period due to postoperative glare/halos. This subject was excluded from data used for the visual analysis. Postoperatively across the seven study centres 50 patients completed at least 12 months of prospective follow-up visits as planned. The mean preoperative CNVA with $\mathrm{a}+2.5 \mathrm{D}$ addition at a reading distance of $40 \mathrm{~cm}$ was $0.23 \pm 0.12$ (decimal). Postoperatively, the UNVA at $15 \mathrm{~cm}$ for reading was $0.42 \pm 0.29$ at day $1,0.53 \pm 0.32$ at day 7 , $0.59 \pm 0.33$ at 1 month, $0.59 \pm 0.33$ at 3 months, $0.52 \pm 0.33$ at 6 months and $0.57 \pm 0.33$ at 1 year. The preoperative screening test of measuring CNVA at $15 \mathrm{~cm}$ with a +6.0 $\mathrm{D}$ addition (estimated vision) showed a mean CNVA of $0.58 \pm 0.31$ which is very similar to the postoperative UNVA measured at $15 \mathrm{~cm}$, confirming that the preoperative near vision screening process is simple and effective

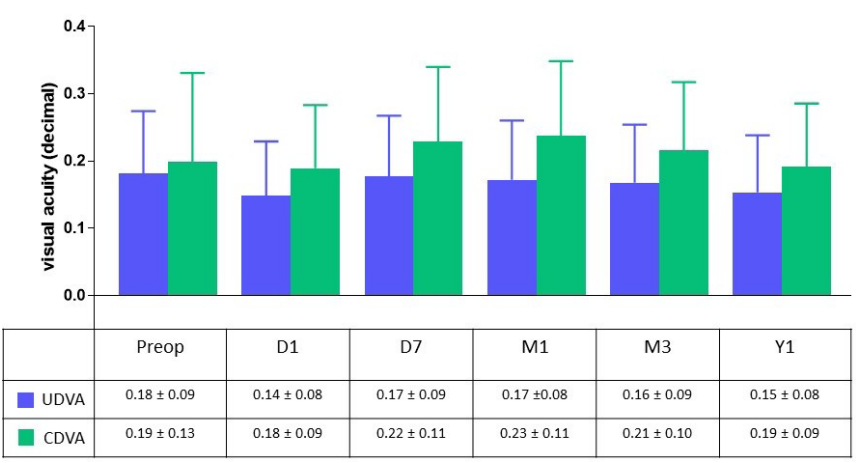

Figure 4 Graph illustrating the preoperative and postoperative uncorrected and corrected distance visual acuity at various time gates. CDVA, corrected distance visual acuity; UDVA, uncorrected distance visual acuity.

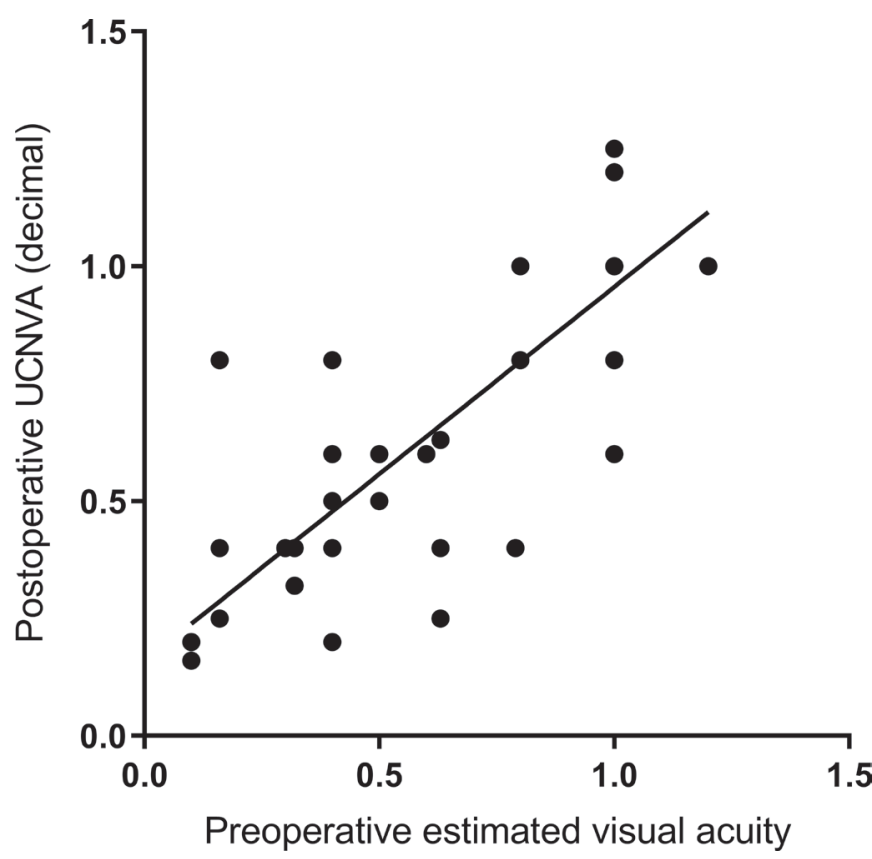

Figure 3 Graph depicting the Spearman coefficient of rank correlation between the preoperative estimated and the postoperative measured visual acuity at 3 months. Calculation found significant association between the 2 variables $(p<0.0001)$.

in predicting the postoperative UNVA (figure 2). Spearman's coefficient of rank correlation was used to correlate the association between the preoperatively estimated CNVA (with a $6.0 \mathrm{D}$ reading addition at $15 \mathrm{~cm}$ ) and the postoperative CNVA at 3 months. The statistical test found a significant correlation between these two variables $(\mathrm{p}<0.0001)$ with a Spearman $\mathrm{r}=0.80$ (figure 3 ).

The mean UDVA (in decimal) preoperatively was $0.18 \pm 0.09$ and $0.14 \pm 0.08$ at day $1,0.17 \pm 0.09$ at day 7 , $0.17 \pm 0.08$ at 1 month, $0.16 \pm 0.09$ at 3 months, $0.16 \pm 0.08$ at 6 months and $0.15 \pm 0.08$ at 12 months postoperatively. The mean CDVA was $0.19 \pm 0.13$ preoperatively and $0.18 \pm 0.09$ at day $1,0.22 \pm 0.11$ at day $7,0.23 \pm 0.11$ at 1 month, $0.21 \pm 0.10$ at 3 months, $0.20 \pm 0.09$ at 6 months and $0.19 \pm 0.09$ at 1 year postoperatively (figure 4 ). This stable CDVA postoperatively confirms that the SML does not affect the CDVA. There was no change in the mean intraocular pressure measurements preoperatively and postoperatively. During the follow-up period there was no change to the foveal thickness on macular OCT (figure 5).

\section{DISCUSSION}

Visual rehabilitation of patients with AMD continues to pose a challenge to the treating clinician, patients and the society in general. Patients with end-stage AMD have severe visual impairment due to bilateral central scotomas resulting from GA, disciform scar or both. These patients experience a substantial reduction in their quality of life, resulting in increased dependency on caregivers and secondary depression. ${ }^{18-20}$ A Canadian study reported 


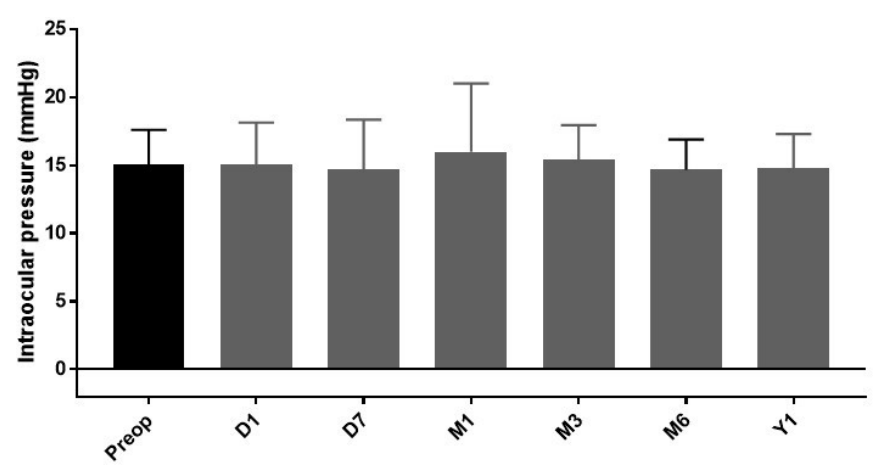

Figure 5 Mean change in the foveal thickness on optical coherence tomography (OCT) over the study period of 1 year.

a $63 \%$ reduction in the quality of life for patients with advanced AMD, which is similar to those reported by patients suffering from severe stroke or advanced prostatic cancer. ${ }^{20}$

Traditionally, visual rehabilitation for patients with AMD has been attempted with low visual aids (LVA) in the form of stronger bifocals $(\geq 3.50 \mathrm{D})$, handheld or stand magnifiers, monocular telescopes, binocular spectacle telescope and electronic visual display units. ${ }^{21}$ The idea of using IOL to provide some kind of magnification for this subset of patients is not new. Choyce in 1964 first described the combination of an anterior chamber lens and positive spectacles. ${ }^{22}$ This combination with a posterior chamber IOL was then proposed by Donn and Koester. ${ }^{23}$ Since then, other authors have reported on using this strategy with varying degrees of success. ${ }^{9} 10$ In the last two decades, there has been interest in the use of intraocular telescopes to provide magnification. In 1997, Lipshitz et al developed the miniature Galilean telescope termed intraocular miniature telescope that functions intraocularly as a telephoto lens system in conjunction with the refractive power of the cornea. ${ }^{24}$ The prosthesis is a fixed-focus telescopic system which comprised ultraprecision quartz glass-wide angle micro-optics. The unique geometry and substantial dimensions of the device (The device cylinder is $4.4 \mathrm{~mm}$ long and 3.6 $\mathrm{mm}$ in diameter and weighs $115 \mathrm{mg}$ in air and $60 \mathrm{mg}$ in aqueous) require a very large incision size of 11-12 mm, and peripheral iridectomy. ${ }^{12}$ Although the device seems to provide stable best corrected distance and near vision, this procedure has several surgery-related complications including surgically induced astigmatism, iris prolapse, iritis, iris damage, iris sphincter damage, zonule rupture diplopia corneal endothelial cell loss and persistent corneal oedema requiring corneal transplantation. ${ }^{11} 12$ Moreover, as a $20^{\circ}-24^{\circ}$ forward field of view is projected onto approximately $55^{\circ}$ of the retina, the peripheral field in the treated eye is markedly reduced. ${ }^{12}$ There are a few reports on the use of dual optic system using two IOLs to create an intraocular Galilean telescopic system, ${ }^{13} 14$ and recently there has been one report on the use of wavefront-optimised IOL (iolAMD Eyemax mono) to provide enhanced quality of vision during cataract surgery in patients with AMD. However, it is unclear how the optics of this IOL works. ${ }^{15}$

Ideally, IOL designed to provide intraocular magnification for patients with AMD should have the following characteristics: to provide sufficient magnification for near vision without affecting the distance vision, be safe and easy to implant, should not affect the peripheral vision field, be reversible and, finally, be widely available and affordable to the population. One such device is the SML. One of the major advantages of this IOL is that it can be implanted as add-on IOL in previously pseudophakic eyes and that the procedure is easily reversible. Cataract and age-related macular degeneration (AMD) are very common eye diseases in the elderly. Many patients are afflicted by both cataract and AMD, and both diseases decrease visual acuity. Cataract surgery alone with standard monofocal IOL has been shown to be effective in improving the vision in patients with coexisting cataract and AMD. ${ }^{25}$ Two of the major drawbacks with the previous intraocular magnifying devices are: first, that they are combined during cataract surgery which we feel is a major confounding factor when analysing the postoperative visual outcomes. As there is evidence to show cataract surgery with standard monofocal IOL improves vision in patients with varying degrees of AMD, ${ }^{25}$ it is unclear whether the postoperative improvement in vision is from the cataract removal or from the magnifying intraocular devices. Second, as all these devices are combined during cataract surgery it excludes a large subset of patients with AMD who are previously pseudophakic. We believe that SML is unique as an intraocular magnifying device as this technology is not combined during cataract surgery. This allows the clinician to effectively assess the improvement in vision following cataract surgery with a standard monofocal IOL and postoperatively assessing the CDVA and CNVA will clearly identify patients who may or may not meet the inclusion criteria for SML. Our multicentre study results show that all the patients who showed improvement in their CNVA preoperatively went on to show improvement in their UNVA postoperatively proving that the preoperative screening tool is simple and yet effective in selecting the subset of patients who will benefit from this technology. Moreover, SML provides the opportunity to treat patients who have been previously pseudophakic with a standard monofocal IOL. In our experience, we noted that subjects benefited from being taught and encouraged to hold their reading material at $15 \mathrm{~cm}$ to enhance their reading potential. Our recommendations for clinicians wishing to incorporate this technology would be that they engage an optometrist experienced in LVAs to train and educate patients to read at $15 \mathrm{~cm}$ with adequate light to enhance the reading potential.

However, a randomised clinical trial with an intentionto-treat analysis comparing SML to the conventional handheld magnifying devise would provide very valuable comparative data. In conclusion, this prospective multicentre clinical trial shows that in a selected subset 
of previously pseudophakic patients with AMD, SML is effective in improving near vision. Further long-term follow-up studies are required to gather more data.

Author affiliations

${ }^{1}$ Department of Ophthalmology, University Hospital, Ayr, UK

${ }^{2}$ University of West of Scotland, Ayr, Scotland, UK

${ }^{3}$ Aurelios Augenzentrum, Recklinghausen, Germany

${ }^{4}$ North View Eye Clinic, Kiel, Germany

${ }^{5}$ ZRENIE Private Eye Center, Sofia, Bulgaria

${ }^{6}$ Department of Ophthalmology, Faculty Hospital of Hradec Králové, HradecKrálové, Czech Rebuplic

${ }^{7}$ Saint Joseph Clinic, Lobbes, Belgium

${ }^{8}$ Department of Ophthalmology, Semmelweis University, Budapest, Hungary

${ }^{9}$ Clinica Retina, Bucharest, Romania

Contributors SS has contributed to the clinical study. SS was the principal investigator.

Funding The authors have not declared a specific grant for this research from any funding agency in the public, commercial or not-for-profit sectors.

Competing interests Gabor Scharioth receives royalty from Medicontur, the manufacturer of the Scharioth macula lens.

Patient consent for publication Not required.

Provenance and peer review Not commissioned; externally peer reviewed.

Open access This is an open access article distributed in accordance with the Creative Commons Attribution Non Commercial (CC BY-NC 4.0) license, which permits others to distribute, remix, adapt, build upon this work non-commercially, and license their derivative works on different terms, provided the original work is properly cited, appropriate credit is given, any changes made indicated, and the use is non-commercial. See: http://creativecommons.org/licenses/by-nc/4.0/.

\section{REFERENCES}

1. Bunce $C$, Xing W, Wormald R. Causes of blind and partial sight certifications in England and Wales: April 2007-March 2008. Eye 2010;24:1692-9

2. Wong WL, Su X, Li X, et al. Global prevalence of age-related macular degeneration and disease burden projection for 2020 and 2040: a systematic review and meta-analysis. Lancet Glob Health 2014;2:e106-16.

3. Pascolini D, Mariotti SP. Global estimates of visual impairment: 2010. Br J Ophthalmol 2012;96:614-8.

4. Holz FG, Strauss EC, Schmitz-Valckenberg S, et al. Geographic atrophy: clinical features and potential therapeutic approaches. Ophthalmology 2014;121:1079-91.

5. Patel HR, Hariprasad SM, Eichenbaum D. Geographic atrophy: clinical impact and emerging treatments. Ophthalmic Surg Lasers Imaging Retina 2015;46:8-13.

6. Age-Related Eye Disease Study 2 Research Group. Lutein + zeaxanthin and omega-3 fatty acids for age-related macular degeneration: the age-related eye Disease Study 2 (AREDS2) randomized clinical trial. JAMA 2013;309:2005-15.

7. Hooper P, Jutai JW, Strong G, et al. Age-related macular degeneration and low-vision rehabilitation: a systematic review. Can J Ophthalmol 2008;43:180-7.

8. Ryan B, Culham L. Fragmented vision. Survey of low vision services in the UK. London: Royal National Institute for the Blind and Moorfields Eye Hospital NHS Trust, 1999.

9. Lizuka M, Gorfinkel J, Mandelcorn M, et al. Modified cataract surgery with telescopic magnification for patients with agerelated macular degeneration. Can J Ophthalmol 2007;42:854-9.

10. Gayton JL, Mackool RJ, Ernest PH, et al. Implantation of multifocal intraocular lenses using a magnification strategy in cataractous eyes with age-related macular degeneration. J Cataract Refract Surg 2012;38:415-8

11. Alió JL, Mulet EM, José M, et al. Intraocular telescopic lens evaluation in patients with age-related macular degeneration. $J$ Cataract Refract Surg 2004;30:1177-89.

12. Hudson HL, Lane SS, Heier JS, et al. Implantable miniature telescope for the treatment of visual acuity loss resulting from end-stage age-related macular degeneration: 1-year results. Ophthalmology 2006;113:1987-2001.

13. Orzalesi N, Pierrottet CO, Zenoni S, et al. The IOL-Vip system: a double intraocular lens implant for visual rehabilitation of patients with macular disease. Ophthalmology 2007;114:860-5.

14. Qureshi MA, Robbie SJ, Tabernero J, et al. Injectable intraocular telescope: pilot study. J Cataract Refract Surg 2015;41:2125-35.

15. Qureshi MA, Robbie SJ, Hengerer FH, et al. Consecutive case series of 244 age-related macular degeneration patients undergoing implantation with an extended macular vision IOL. Eur J Ophthalmol 2018;28:198-203.

16. Scharioth GB. New add-on intraocular lens for patients with agerelated macular degeneration. Journal of Cataract \& Refractive Surgery 2015;41:1559-63.

17. Reiter N, Werner L, Guan J, et al. Assessment of a new hydrophilic acrylic supplementary IOL for sulcus fixation in pseudophakic cadaver eyes. Eye 2017;31:802-9.

18. Schmier JK, Halpern MT, Covert D, et al. Impact of visual impairment on use of caregiving by individuals with age-related macular degeneration. Retina 2006;26:1056-62

19. Williams RAet al. The psychosocial impact of macular degeneration. Arch Ophthalmol 1998;116:514-20.

20. Brown MM, Brown GC, Stein JD, et al. Age-related macular degeneration: economic burden and value-based medicine analysis. Can J Ophthalmol 2005;40:277-87.

21. Decarlo DK, McGwin G, Searcey K, et al. Use of prescribed optical devices in age-related macular degeneration. Optom Vis Sci 2012;89:1336-42. Jr

22. Choyce P. Intraocular lenses and implants. London: HK Lewis, 1964: 156-61.

23. Donn A, Koester CJ. An ocular telephoto system designed to improve vision in macular disease. Eye \& Contact Lens: Science \& Clinical Practice 1986;12:81-5.

24. Lipshitz I, Loewenstein A, Reingewirtz M, et al. An intraocular telescopic lens for macular degeneration. Ophthalmic Surg Lasers 1977;28:513-7

25. Kessel L, Erngaard D, Flesner P, et al. Cataract surgery and agerelated macular degeneration. an evidence-based update. Acta Ophthalmol 2015;93:593-600 


\section{Correction: Implantation of Scharioth macula lens in patients with age-related macular degeneration: results of a prospective European multicentre clinical trial}

Srinivasan S. Implantation of Scharioth macula lens in patients with age-related macular degeneration: results of a prospective European multicentre clinical trial. BMJ Open Ophth 2019;4:e000322. doi: 10.1136/bmjophth-2019-000322.

This article has been corrected since it published Online First. The following co-authors were missing in the published version.

Gabor Scharioth, ${ }^{3}$ Anneliese Riehl, ${ }^{4}$ Ivan V Tanev, ${ }^{5}$ Pavel Rozsival, ${ }^{6}$ Emmanuel Van Acker, ${ }^{7}$ Zoltan Z Nagy, ${ }^{8}$ Florian Balta, ${ }^{9}$ Jana Nekolova, ${ }^{6}$

3 Aurelios Augenzentrum, Recklinghausen, Germany

4 North View Eye Clinic, Kiel, Germany

5 ZRENIE Private Eye Center, Sofia, Bulgaria

6 Department of Ophthalmology, Faculty Hospital of Hradec Králové, Hradec Králové, Czech Rebuplic

7 Saint Joseph Clinic, Lobbes, Belgium

8 Department of Ophthalmology, Semmelweis University, Budapest, Hungary

9 Clinica Retina, Bucharest, Romania

Open access This is an open access article distributed in accordance with the Creative Commons Attribution Non Commercial (CC BY-NC 4.0) license, which permits others to distribute, remix, adapt, build upon this work non-commercially, and license their derivative works on different terms, provided the original work is properly cited, appropriate credit is given, any changes made indicated, and the use is non-commercial. See:http://creativecommons.org/ licenses/by-nc/4.0/

(C) Author(s) (or their employer(s)) 2019. Re-use permitted under CC BY-NC. No commercial re-use. See rights and permissions. Published by BMJ.

BMJ Open Ophth 2019;4:e000322corr1. doi:10.1136/bmjophth-2019-000322corr1

D) Check for updates 